\title{
A Role for RhoB in Synaptic Plasticity and the Regulation of Neuronal Morphology
}

\author{
Kara McNair, ${ }^{1}$ Rosemary Spike, ${ }^{1}$ Clare Guilding, ${ }^{1}$ George C. Prendergast, ${ }^{2}$ Trevor W. Stone, ${ }^{1}$ Stuart R. Cobb, ${ }^{1}$ \\ and Brian J. Morris ${ }^{1}$ \\ ${ }^{1}$ Neuroscience and Molecular Pharmacology, Faculty of Biomedical and Life Sciences, University of Glasgow, Glasgow G12 8QQ, United Kingdom, \\ and ${ }^{2}$ Lankenau Institute for Medical Research, Wynnewood, Pennsylvania 19096
}

Actin-rich dendritic spines are the locus of excitatory synaptic transmission and plastic events such as long-term potentiation (LTP). Morphological plasticity of spines accompanies activity-dependent changes in synaptic strength. Several Rho GTPase family members are implicated in regulating neuronal and, in particular, spine structure via actin and the actin-binding protein cofilin. However, despite expression in hippocampus and cortex, its ability to modulate actin-regulatory proteins, and its induction during aging, RhoB has been relatively neglected. We previously demonstrated that LTP is associated with specific RhoB activation. Here, we further examined its role in synaptic function using mice with genetic deletion of the RhoB GTPase ( $\mathrm{RhoB}^{-1-}$ mice). Normal basal synaptic transmission accompanied reduced paired-pulse facilitation and post-tetanic potentiation in the hippocampus of RhoB ${ }^{-1-}$ mice. Early phase LTP was significantly reduced in $\mathrm{RhoB}^{-/-}$animals, whereas the later phase was unaffected. In wild-type mice $\left(\mathrm{RhoB}^{+/+}\right)$, Western blot analysis of potentiated hippocampus showed significant increases in phosphorylated cofilin relative to nonpotentiated slices, which were dramatically impaired in $\mathrm{RhoB}^{-1-}$ slices. There was also a deficit in phosphorylated Lim kinase levels in the hippocampus from RhoB ${ }^{-1-}$ mice. Morphological analysis suggested that lack of RhoB resulted in increased dendritic branching and decreased spine number. Furthermore, an increase in the proportion of stubby relative to thin spines was observed. Moreover, spines demonstrated increased length along with increased head and neck widths. These data implicate RhoB in cofilin regulation and dendritic and spine morphology, highlighting its importance in synaptic plasticity at a structural and functional level.

\section{Introduction}

Rho GTPases form part of a complex signaling network maintained by permutations of guanine nucleotide exchange factors, GTPase activating proteins, and GDP dissociation inhibitors. Through numerous effectors, they regulate various cellular processes (Jaffe and Hall, 2005), including the control of the actin cytoskeleton (Hall, 1998).

Of the 22 Rho GTPases identified to date, RhoA, Rac1, and $\mathrm{Cdc} 42$ are the best characterized with respect to their influence over actin dynamics. In neurons, $\mathrm{Cdc} 42$ and $\mathrm{Rac} 1$ are required for neurite formation (Threadgill et al., 1997; Sarner et al., 2000). Conversely, lack of RhoA promotes dendrite formation (Lee et al., 2000) and increased RhoA reduces dendritic growth in hippocampal neurons via Rho kinase (ROCK) (Tigyi et al., 1996; Lee et al., 2000; Nakayama et al., 2000). Indeed, ROCK inhibitors induce robust neurite outgrowth, accompanying rapid cofilin dephosphorylation (Zhang et al., 2006).

Received 0ct. 30, 2009; revised Jan. 14, 2010; accepted Jan. 21, 2010.

This work was supported by the Biotechnology and Biological Sciences Research Council. We thank John Pediani for assistance with the use of AutoDeblur software.

Correspondence should be addressed to Prof. Brian J. Morris, Neuroscience and Molecular Pharmacology, Faculty of Biomedical and Life Sciences, University of Glasgow, Glasgow G12 8QQ, UK. E-mail: B.Morris@bio.gla.ac.uk.

C. Guilding's present address: Faculty of Life Sciences, Stopford Building, University of Manchester, Oxford Road, Manchester M13 9PT, UK.

DOI:10.1523/JNEUROSCI.5386-09.2010

Copyright $\odot 2010$ the authors $\quad 0270-6474 / 10 / 303508-10 \$ 15.00 / 0$
Spine morphogenesis also requires precise Rho GTPasemediated actin control. Racl affects the size, shape, and number of spines (Luo et al., 1996; Nakayama et al., 2000). Additionally, a loss-of-function mutation of Cdc42 results in reduced spine density (Scott et al., 2003). Although RhoA is primarily thought to regulate dendritic structures (Nakayama et al., 2000), spine size and density are also under RhoA regulation (Tashiro et al., 2000).

The dynamic structure of dendritic spines is vital for synaptic function. Indeed, several plasticity-inducing stimuli result in spinogenesis and the enlargement or retraction of existing spines (Matsuzaki et al., 2004; Nägerl et al., 2004; Okamoto et al., 2004; Zhou et al., 2004) via actin modifications (Fukazawa et al., 2003; Lin et al., 2005). Actin-depolymerizing factor/cofilin is phosphorylated/inhibited in spines shortly after LTP induction (Chen et al., 2007). Moreover, impaired cofilin regulation results in LTP inhibition (Fukazawa et al., 2003).

It is tacitly assumed that RhoA is responsible for ROCK activation in the CNS. However, RhoB, which has been relatively neglected in the neuroscience arena and is highly expressed in the brain (O'Kane et al., 2003a), can also activate ROCK (Leung et al., 1996). Additionally, RhoB can activate the actin regulatory protein mDia2 on endosomes (Wallar et al., 2007), and RhoB-containing endosomes harbor proteins involved in actin regulation (Sandilands et al., 2004). Furthermore, the involvement of RhoB in programmed cell death (Liu et al., 2000) may occur via activation of mDia2 (Kamasani et al., 2007). Indeed, RhoB is emerging as a key player in CNS injury (Brabeck et al., 2003, 2004) and aging (Yoon 
et al., 2007). Evidence that RhoB modulates Alzheimer's diseaserelated genes suggests a link between this GTPase and dementia (Kamasani and Prendergast, 2005).

We have previously demonstrated that LTP is associated with specific RhoB activation (O'Kane et al., 2003b). To assess the contribution of RhoB to synaptic plasticity mechanisms, we investigated the electrophysiological and morphological consequences of RhoB gene deletion and found that reduced synaptic plasticity accompanies reduced cofilin phosphorylation. Furthermore, dramatic alterations in neuronal cytoarchitecture are observed. Together, these data suggest that RhoB plays an important role in synaptic plasticity and does so as a result of its significant influence over neuronal morphology.

\section{Materials and Methods}

RhoB homozygous null mice. Mice heterozygous for deletion of the RhoB gene (Liu et al., 2001) were generously provided by Prof. G. Prendergast (Lankenau Institute for Medical Research, Wynnewood, PA). Following extensive backcrossing onto the C57BL/6J substrain, heterozygotes were used to provide homozygous and wild-type littermates for further breeding. Intermittent breeding of heterozygotes was conducted to minimize the chances of any genetic drift. The genotype of mice was determined by PCR (Liu et al., 2001).

Nissl staining. Male $\mathrm{RhoB}^{+/+}$or $\mathrm{RhoB}{ }^{-/-}$mice (4-8 weeks) were deeply anesthetized $(1500 \mathrm{mg} / \mathrm{kg}$ urethane, i.p.) and killed by cervical dislocation in accordance with local ethical guidelines and UK legislation. Brains were rapidly transferred to dry ice where they were snap frozen and subsequently cut into $20-\mu$ m-thick coronal sections on a cryostat. The sections throughout the hippocampus were mounted on gelatin-coated slides and allowed to air dry for $30 \mathrm{~min}$.

The pyramidal cells in the hippocampus of rats were visualized by Nissl staining. The mounted sections were rehydrated in distilled water and submerged in $0.5 \%$ cresyl violet solution for about $30 \mathrm{~min}$ until the desired depth of staining was achieved.

Hippocampal slice preparation, electrophysiology, and intracellular labeling. Male RhoB ${ }^{+/+}$or RhoB ${ }^{-/-}$mice (4-8 weeks) were deeply anesthetized ( $1500 \mathrm{mg} / \mathrm{kg}$ urethane, i.p.) and killed by cervical dislocation in accordance with local ethical guidelines and UK legislation. Brains were rapidly transferred into ice-cold $\left(0-3^{\circ} \mathrm{C}\right)$ and oxygenated $\left(95 \% \mathrm{O}_{2}, 5 \%\right.$ $\mathrm{CO}_{2}$ ) artificial cerebrospinal fluid of the following composition (in mM): $\mathrm{NaCl}, 124 ; \mathrm{KCl}, 3 ; \mathrm{NaHCO}_{3}, 26 ; \mathrm{NaH}_{2} \mathrm{PO}_{4}, 1.25 ; \mathrm{MgSO}_{4}$, 1; D-glucose, $10 ; \mathrm{CaCl}_{2}, 2$. Transverse whole brain slices $(300 \mu \mathrm{m})$ were prepared and hippocampal regions were dissected free from surrounding brain tissue before being transferred to a submerged tissue chamber in a humidified and oxygen-enriched $\left(95 \% \mathrm{O}_{2}, 5 \% \mathrm{CO}_{2}\right)$ atmosphere at $37^{\circ} \mathrm{C}$, as described previously (O'Kane et al., 2004; McNair et al., 2006). Input/ output response curves were generated before long-term potentiation (LTP) or paired-pulse facilitation (PPF) experiments by administering 11 pulses of increasing current intensity $(0-5 \mathrm{pA})$ and recording corresponding EPSP responses within stratum radiatum of the CA1 area of the hippocampus. PPF was measured by giving two single pulses $10-500 \mathrm{~ms}$ apart and determining the ratio of pulse 2/pulse 1 (P2/P1) EPSP responses. To induce LTP, bulk electrical stimulation of the CA3-CA1 pyramidal cell synapses was delivered using stimulation electrodes placed within stratum radiatum of area CA1 of the hippocampus. Single stimuli were delivered at low frequency $(0.033 \mathrm{~Hz})$ and, upon obtaining a $30 \mathrm{~min}$ stable baseline of synaptic field potential recordings, a high-frequency stimulation (HFS) paradigm was applied (100 pulses at $100 \mathrm{~Hz}, 1 \mathrm{~s})$ to produce an enduring synaptic potentiation. Low-frequency baseline recordings continued to be monitored until the tissue was removed from the recording chamber $15 \mathrm{~min}$ after the high-frequency burst, and the $\mathrm{CA} 1$ regions were isolated and stored at $-70^{\circ} \mathrm{C}$ before Western blot analysis. Control slices were not subjected to HFS, but received continual low-frequency stimulation $(0.033 \mathrm{~Hz})$ for the duration of the recording.

Using standard transverse hippocampal slices, CA1 pyramidal neurons were filled intracellularly with Neurobiotin (Vector Laboratories). Recording electrodes were pulled from standard wall borosilicate tubing using a Brown and Flaming-type horizontal electrode puller (Sutter Institute). Electrodes for intracellular recordings were filled with $1.5 \mathrm{M}$ potassium methylsulphate $/ 2 \%$ neurobiotin and exhibited a DC resistance of $80-150 \mathrm{M} \Omega$. CA1 pyramidal cells were impaled and held at $-70 \mathrm{mV}$. After stably impaling the neuron, neurobiotin was ionophoresed into the cell with a depolarizing current for $15 \mathrm{~min}$ before rapid fixation in 4\% PFA overnight and then embedded in gelatin and sectioned at $40 \mu \mathrm{m}$ with a Vibratome (TPI). Labeled neurons were rendered fluorescent by incubation in a rhodamine-conjugated streptavidin (Jackson ImmunoResearch Laboratories) solution overnight. Sections were then mounted without dehydration in Vectashield media (Vector Laboratories), coverslipped, and sealed. Slides were stored at $-20^{\circ} \mathrm{C}$ before further analysis.

Confocal microscopy. Sections were first viewed with epifluorescence through a $20 \times$ lens to locate labeled cells and then scanned with a BioRad MRC1024 confocal microscope with a krypton-argon laser. For all labeled cells, stacks of confocal images were scanned sequentially with a $40 \times$ oil immersion lens and a $z$-separation of $0.3 \mu \mathrm{m}$. Excitation for the far-red (rhodamine) signal was provided by a $\mathrm{HeNe}(633 \mathrm{~nm})$ laser line (emission window, 650-710 nm). Optical sections were averaged four times to reduce noise. Images were acquired at a digital size of $1024 \times$ 1024 pixels with a $3 \times$ optical zoom. Confocal assistant was used to convert Biorad.pic files to individual Tiff files suitable for further analysis.

Image analysis. Reconstruct software was downloaded with permission from Synapse Web, (Kristen Harris, Principal Investigator, University of Texas, Austin, TX; http://synapses.clm.utexas.edu/). Section thickness and pixel size was assigned to each individual file to allow for representative and accurate measurement. Fluorescence generated by rhodaminelabeled pyramidal cells was highlighted using the wildfire tool. Then, using the zoom capability, individual spines were visualized and measured using the $z$-tools component of the software. Three measurements for each parameter (neck width, head width, and spine length) were taken and averaged. In addition, dendritic length was also measured using the $z$-tools function, which allowed for accurate measurement through stacks of images. Only spines visibly perpendicular to the dendritic shaft were used in analysis. Spines were then assigned to specific subtypes (mushroom, thin, stubby), as described previously (Harris et al., 1992), using the following criteria: spines that demonstrated a large head-to-neck ratio $(>1.4)$ were defined as mushroom-type spines. Those spines whose length-to-neck ratio was $>1.4$ were defined as thin-type spines. Stubby-shaped spines were labeled as such if their head-to-neck and length-to-neck ratio was $\leq 1$. Those spines that did not fit into any of the above-described categories were discarded from further analysis (see Fig. 5A, $B$ ). Images were deconvolved as follows: out-of-focus light was removed from the $z$-series of images using AutoQuant blind iterative and constrained algorithm (AutoDeblur software version 9.3.6; AutoQuant Imaging/Media Cybernetics) where a point spread function measured directly from the raw dataset reassigns the out-of-focus light to its expected point of origin. Maximum $x-y$ projection views were then constructed using AutoQuant AutoVisualize software (AutoQuant Imaging/ Media Cybernetics).

Golgi-Cox analysis of $R h o B^{-1-}$ and $R h o B^{+1+}$ mouse brains. GolgiCox staining was performed using the FD Rapid GolgiStain kit (FD NeuroTechnologies) as per the manufacturer's instructions. Briefly, male $\mathrm{RhoB}^{-1-}$ and RhoB ${ }^{+/+}$mice (ages 5-8 months) were deeply anesthetized before cervical dislocation. Mouse brains were then rapidly removed, rinsed briefly in water, and immersed in impregnation solution at room temperature for 2 weeks in the dark. Impregnation solution was refreshed after the initial $24 \mathrm{~h}$ of immersion. The tissue is then transferred into solution $\mathrm{C}$ and stored at $4^{\circ} \mathrm{C}$ for at least $48 \mathrm{~h}$ in the dark. Again, the solution was replenished after the first $24 \mathrm{~h}$ of immersion. Sections were then cut at $120 \mu \mathrm{m}$ thickness on a cryostat with chamber temperature set at $-27^{\circ} \mathrm{C}$. Each section was then mounted on gelatin-coated slides using solution $\mathrm{C}$ before being dried at room temperature, dehydrated, and cleared in xylene solution before being mounted in Histomount (ThermoFisher Scientific). From each genotype we used three mice and studied 70 and 71 cortical neurons in $\mathrm{RhoB}^{+/+}$and $\mathrm{RhoB}^{-/-}$mice, respectively. Pyramidal neurons from layer II/ III of the cortex and the CA1 region of the hippocampus were observed by an investigator blind 
to the genotype under a Nikon Eclipse E400 microscope and drawn on a two-dimensional plane by using a $40 \times$ objective lens. To ensure relative neuron completeness, cells were selected that were located close to the center of the section and had pyramidal cell morphology with the primary apical dendritic trunk orientated in line with the plane of the section. Analysis was limited to a $220 \mu \mathrm{m}$ radius, and cells with significant processes cut at the surface of the section were excluded from the analysis. Despite the most distal aspects of the dendritic arbor not being sampled with this approach, the method nevertheless allows the comparison of salient features of dendritic morphology in randomly sampled neurons from both genotypes. Branching was studied by Sholl analysis. A transparent grid with concentric rings (20 $\mu \mathrm{m}$ apart) was placed over the drawing with the smallest circle centered on the cell soma. Sholl measurements were obtained by quantifying the number of intersections crossing each $20 \mu \mathrm{M}$ radius ring from the soma. To calculate spine density, dendrites with spines were traced using a $100 \times$ oil immersion lens, and the number of spines along the length was counted to give a measure of spines $/ 10 \mu \mathrm{m}$ length.

Western blot analysis. Western blot studies were performed as described previously (Simpson and Morris, 2000; James et al., 2006). Proteins from either whole brain or isolated CA1 regions obtained from hippocampal slices used in electrophysiology experiments were extracted with $5 \times \mathrm{Mg}^{2+}$-free lysis buffer (Millipore) diluted in $10 \%$ glycerol with protease inhibitors added fresh. Cellular extracts were then centrifuged at $12,000 \mathrm{rpm}$ for $10 \mathrm{~min}$ at $4^{\circ} \mathrm{C}$, and the supernatants were collected. The protein concentration of each individual sample was determined using a Bio-Rad protein assay kit (Bio-Rad) and concentrations normalized to the lowest concentration sample. Samples were then heated to $95^{\circ} \mathrm{C}$ in Laemmli sample buffer (2\% SDS, 10\% glycerol, $100 \mathrm{~mm}$ DTT, $60 \mathrm{~mm}$ Tris-HCl, pH 6.8, 0.01\% bromophenol blue) before separation by SDSPAGE in a $4-12 \%$ polyacrylamide gel and transfer to a polyvinylidene difluoride membrane. Protein bands were visualized with Ponceau $S$ to verify the quantity of the samples loaded. Blots were washed with TBST buffer (120 mm Tris- $\mathrm{HCl}, \mathrm{pH} 7.5,150 \mathrm{~mm} \mathrm{NaCl}, 0.05 \%$ Tween 20$)$ and then placed in TBST buffer supplemented with $3 \%$ skimmed milk and blocked for $2.5 \mathrm{~h}$ at room temperature. Blots were then incubated with either rabbit polyclonal anti-RhoB (1:1000) (Santa Cruz Biotechnology), anti-CDC42 (1:1000) (Abcam), anti-Racl (1:1000), anti-pCofilin (1: $500)$, anti-pLIMK (1:1000), or anti-total cofilin (1:1000) antiserum (Cell Signaling Technology) overnight at $4^{\circ} \mathrm{C}$ with constant agitation. After washing the blots three times with TBST, membranes were incubated with horseradish peroxidase-conjugated anti-rabbit IgG antibody (1:2000, Millipore) for $1 \mathrm{~h}$ and washed again as described previously. Membrane-bound secondary antibodies were detected using the ECL Plus procedure developed by GE Healthcare Life Sciences. Integrative optical density readings were obtained using NIH Image (W. Rasband, National Institutes of Health, Bethesda, MD), and differences in specific density between $\mathrm{RhoB}^{+/+}$and mutant animals were analyzed for statistical significance as described (Rakhit et al., 2005; James et al., 2006). Where the number of samples was too great to be run on a single gel, band intensities were expressed as a percentage of the mean band intensity from the control $\mathrm{RhoB}^{+/+}$group on that gel. All data are expressed as mean \pm SEM.

RhoA activation assay. The RhoA activation assay was performed as described in the manufacturer's instructions (Millipore). Briefly, tissue from both $\mathrm{Rho}^{+/+}$and $\mathrm{RhoB}^{-/-}$hippocampi was lysed in a $\mathrm{Mg}^{2+}$ lysis buffer. Cleared lysates were subjected to positive $(100 \times \mathrm{GTP} \gamma \mathrm{S})$ or negative $(100 \times$ GDP) controls. Lysates in which active RhoA levels were to be determined were incubated with RhoA protein binding domain agarose beads that, following a short incubation period, were spun down, isolated from supernatant, and washed with $\mathrm{Mg}^{2+}$ lysis buffer. The agarose beads were resuspended in Laemmli reducing sample buffer, boiled for $5 \mathrm{~min}$, and pelleted. Both pull down extract and supernatant were loaded onto nitrocellulose membranes (as previously described) and probed with an HRP-conjugated anti-RhoA primary antibody (Santa Cruz Biotechnology).

Immunocytochemistry. Cultured cortical-hippocampal neurons were fixed with $100 \%$ methanol at $-20^{\circ} \mathrm{C}$ for $20 \mathrm{~min}$. Following PBS washes, nonspecific binding was blocked with a $60 \mathrm{~min}$ room temperature incu-

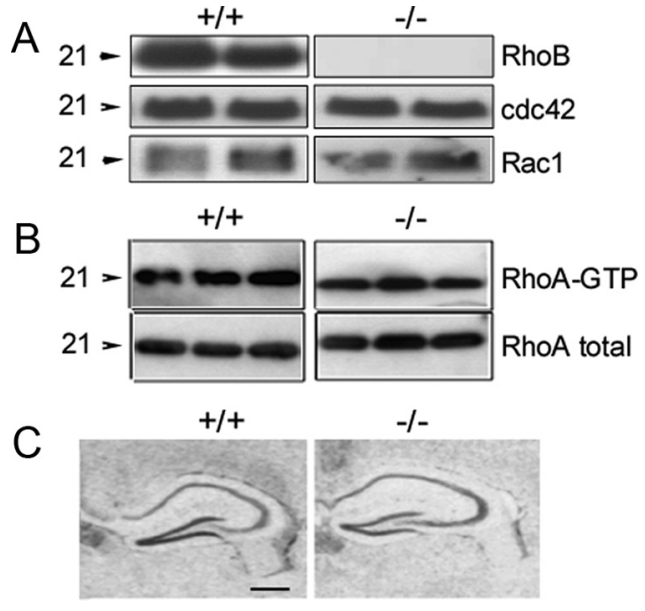

Figure 1. Effect of RhoB gene deletion on Rho GTPase levels and gross hippocampal morphology. $A$, Western blot images illustrating that the complete absence of the RhoB protein in brain tissue from $\mathrm{RhoB}^{-1-}(-/-)$ mice compared with $\mathrm{RhoB}^{+/+}(+/+)$littermates has no effect on other Rho GTPases, including Rac1 and CDC42. $B$, No difference in the levels of active RhoA (RhoA-GTP) or total RhoA in hippocampal tissue from $\mathrm{RhOB}^{-1-}$ and RhoB ${ }^{+/+}$littermate controls was observed. C, Comparable coronal sections ( $20 \mu \mathrm{m}$, frozen) from males were processed for Nissl staining. Note that the structures of the hippocampus are similar in both $\mathrm{RhoB}^{-l-}$ and RhoB ${ }^{+/+}$mice. Scale bar, $500 \mu \mathrm{m}$. Numbers represent size markers (kilodaltons).

bation with $15 \%$ goat serum followed by an overnight $4{ }^{\circ} \mathrm{C}$ incubation with primary antibody solution containing either a rabbit polyclonal anti-RhoB/mouse monoclonal anti-synaptophysin primary combination or rabbit polyclonal anti-RhoB/mouse monoclonal anti-PSD-95 (postsynaptic density protein 95) primary combination. Cells were then incubated for $60 \mathrm{~min}$ at room temperature in the dark with Alexa 594 anti-rabbit secondary to label RhoB or Alexa 488 anti-mouse secondary (Invitrogen) to label either synaptophysin or PSD-95. Cells were coverslipped using Vectashield and visualized on a confocal microscope (see previous description) using a $40 \times$ oil-immersion lens and a $z$-separation of $1 \mu \mathrm{m}$. Excitation was provided by a $\mathrm{HeNe}(633 \mathrm{~nm})$ laser line for the far-red (rhodamine) signal and $488 \mathrm{~nm}$ laser line for the green signal. Optical sections were averaged four times to reduce noise. Images were acquired at a digital size of $512 \times 512$ pixels with a $1 \times$ optical zoom.

Statistical analysis. Data from the PPF, post-tetanic potentiation (PTP), LTP, Western blot, and spine count experiments were all analyzed using a two-way ANOVA with Tukey's post hoc analysis. Sholl data were analyzed using a four-way ANOVA with Tukey's post hoc analysis. The Kolmogorov-Smirnoff test was used to analyze the spine morphology data. In all cases, statistical significance was defined as $p<0.05$. Statistical analysis was performed using Minitab software (version 10) for ANOVA analysis and Kolmogorov-Smirnov software (http://www.physics.csbsju. edu/stats/KS-test.html) for Kolmogorov-Smirnov analysis. All data are presented as mean \pm SEM.

\section{Results}

Following our observation that RhoB is selectively activated via NMDA receptors during hippocampal LTP (O'Kane et al., 2003 b), we sought to assess possible functions for this molecule in synaptic transmission, synaptic plasticity, and related events in mice with deletion of the RhoB gene.

\section{Gross morphology of RhoB ${ }^{-/-}$mouse brains}

Western blot analysis confirmed the deletion of the RhoB protein in the brains of RhoB ${ }^{-1-}$ mice (Fig. $1 A$ ). Furthermore, specific deletion of this Rho GTPase did not affect the levels of other related family members, including Rac1, cdc42, or RhoA (Fig. 1A,B). Since RhoA is very highly homologous to RhoB, we additionally checked the amount of active GTP-bound RhoA (RhoA-GTP) in hip- 


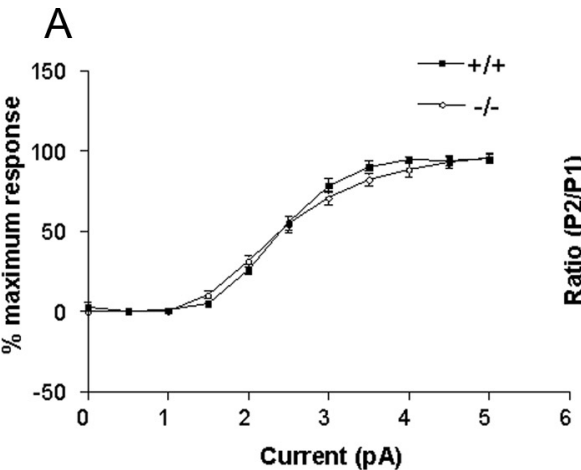

B
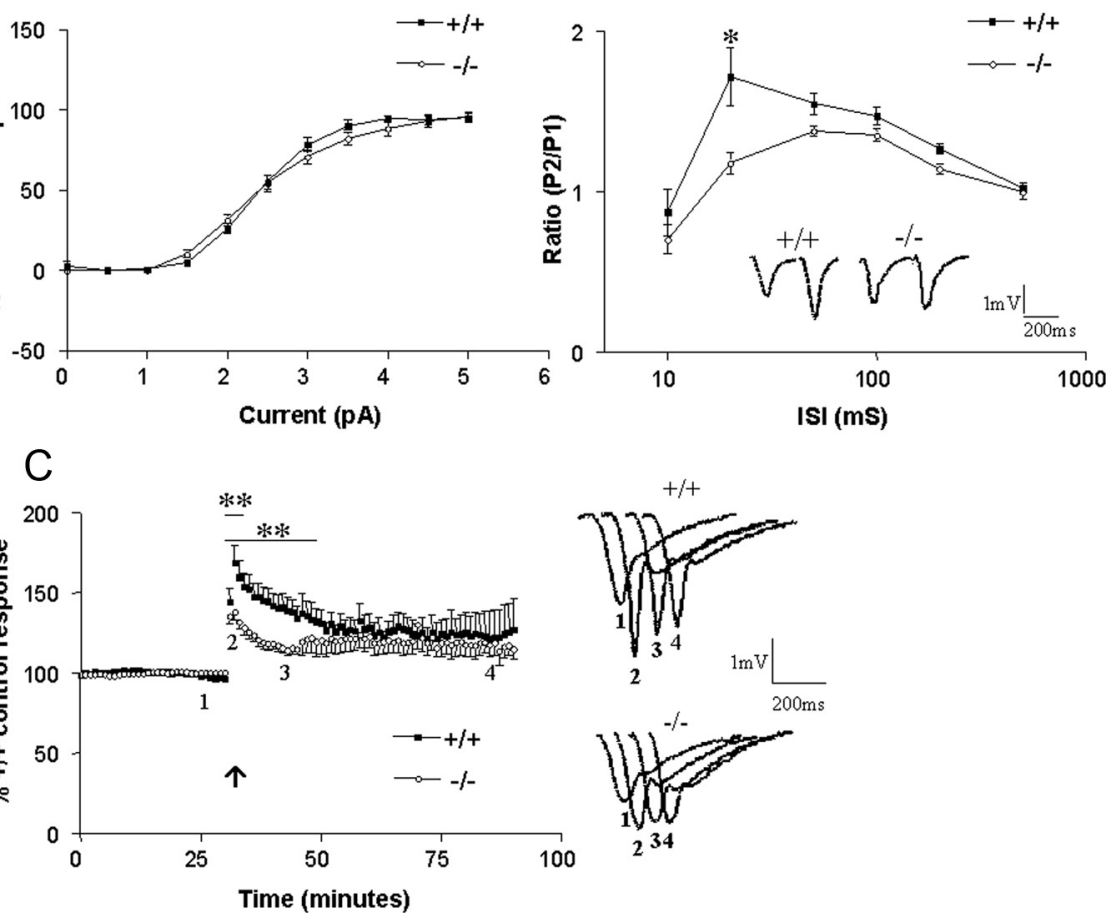

Early phase potentiation of the synaptic response (eLTP) measured $15 \mathrm{~min}$ after a single HFS was significantly reduced in slices from $\mathrm{RhoB}^{-1-}$ mice compared with those from $\mathrm{RhoB}^{+/+}$animals $\left(\mathrm{RhoB}^{+/+}, 139.1 \pm 3.25 ; \mathrm{RhoB}^{-/-}\right.$, $118.1 \pm 1.48$ ) (Fig. 2C). Conversely, a later phase LTP (ILTP) measured 60 min after HFS showed no significant difference in the levels of potentiation between $\mathrm{RhoB}^{-1-}$ and RhoB ${ }^{+/+}$slices $\left(\mathrm{RhoB}^{+/+}, 133.0 \pm 7.6 ; \mathrm{RhoB}^{-/-}\right.$, $117.3 \pm 7.6)$ (Fig. 2C).

\section{RhoB localization}

We sought to elucidate the exact cellular location of RhoB in cortical hippocampal neurons using immunocytochemistry techniques. Using cultured neurons derived from $\mathrm{RhoB}^{+/+}$animals, we probed for RhoB alongside the presynaptic and postsynaptic markers synaptophysin and PSD-95, respectively (Fig. $3 A, B$ ). We observed a colocalization with the postsynaptic marker PSD-95, strongly suggesting a postsynaptic location for RhoB. This was further confirmed by the apposition, rather than colocalization, of RhoB with the presynaptic marker synaptophysin (Fig. 3A,B).

\section{Analysis of cofilin and Lim kinase phosphorylation}

Extensive research has revealed that LTP induction and/ or maintenance is highly dependent on the dynamic nature of actin-rich protrusions, namely dendritic spines (Fukazawa et al., 2003). In light of compared with their RhoB ${ }^{+/+}$counterparts. Representative EPSP traces from RhoB ${ }^{+1+}$ and RhoB ${ }^{-1-}$ animals at $t=-5(1)$, 2 (2), 15 (3), and $60 \mathrm{~min}(4)$ show that the early deficit in synaptic potentiation is recovered over time. Data are expressed as mean \pm SEM $\left[n=9-19,{ }^{*} p<0.05,{ }^{* *} p<0.01\right.$ : two-way ANOVA followed by Tukey's post hoc analysis at $t=2 \min (\mathrm{PTP}), t=$ $15 \mathrm{~min}$ (eLTP), $t=60 \mathrm{~min}$ (ILTP) compared with $t=-5 \min$ (baseline)].

pocampal tissue, but again found no significant change in the RhoB $^{-1-}$ mice (Fig. $1 B$ ). Subsequent studies compared the gross morphology of $\mathrm{RhoB}^{-/-}$and $\mathrm{RhoB}^{+/+}$mouse brains. No overt alterations were noted in brain size. Furthermore, examination of hippocampal tissue sections previously subjected to Nissl staining, commonly used to identify basic neuronal structure, showed overtly normal structure in all brain regions, including the hippocampus (Fig. 1C).

\section{Electrophysiology in $\mathrm{RhoB}^{-/-}$and $\mathrm{RhoB}^{+/+}$ hippocampal slices}

Initial experiments investigated the electrophysiological properties of hippocampal transmission. Input/output curves, used as a measure of basal synaptic transmission, showed no shift in the response obtained from $\mathrm{RhoB}^{-/-}$hippocampal slices compared with slices from $\mathrm{RhoB}^{+/+}$mice (Fig. $2 A$ ). Next, we examined PPF, routinely used as a measure of presynaptic function resulting from residual calcium in the presynaptic terminal. In hippocampal slices from $\mathrm{RhoB}^{-1-}$ mice, PPF was significantly impaired at an interstimulus interval of $25 \mathrm{~ms}$ when compared with slices from $\mathrm{RhoB}^{+/+}$animals (ratio of $\mathrm{P} 2 / \mathrm{P} 1: \mathrm{RhoB}^{+/+}, 1.72 \pm 0.18$; $\mathrm{RhoB}^{-1-}, 1.18 \pm 0.07$ ) (Fig. 2 B). Similarly, a significant decrease in post-tetanic potentiation, measured $2 \mathrm{~min}$ after HFS, was observed in $\mathrm{RhoB}^{-1-}$ mice compared with $\mathrm{RhoB}^{+/+}$controls $\left(\mathrm{RhoB}^{+/+}\right.$, $\left.157.43 \pm 6.79 ; \mathrm{RhoB}^{-/-}, 134.77 \pm 3.48\right)($ Fig. $2 C)$. this, we set out to investigate whether or not cofilin, an actinbinding protein found localized to dendritic spines and previously shown to be involved in LTP and spine morphology (Chen et al., 2007), was implicated in HFS-induced LTP in RhoB $^{+/+}$ mice and whether or not any involvement was altered in the $\mathrm{RhoB}^{-1-}$ mouse. In addition we investigated the possibility that an upstream effector of cofilin, Lim kinase (LIMK) was also involved in this process. Western blot analysis for both pCofilin and pLIMK was performed on hippocampal CA1 regions taken from slices $15 \mathrm{~min}$ after they were subjected to a single high-frequency stimulation. CA1 regions from control hippocampal slices (not subjected to HFS, but given $0.033 \mathrm{~Hz}$ stimulation for the duration of experiment) were also harvested $45 \mathrm{~min}$ from the start of recordings. In $\mathrm{RhoB}^{+/+}$animals there was a significant increase in the amount of pCofilin in slices subjected to eLTP compared with levels in control tissue $\left(\mathrm{RhoB}^{+/+}\right.$control, $100.5 \pm 19.6 \%$; $\mathrm{RhoB}^{+/+}$LTP, $\left.172.8 \pm 25.4 \%\right)$. This increase was absent in the hippocampal slices of $\mathrm{RhoB}^{-/-}$mice $\left(\mathrm{RhoB}^{-/-}\right.$control, $110.9 \pm$ 24.1\%; RhoB ${ }^{-1-}$ LTP, $125.4 \pm 45.2 \%$ ) (Fig. 4Ai,Aii). This suggests that RhoB activation is essential for cofilin phosphorylation during hippocampal LTP. There was a tendency for increased LIMK phosphorylation after LTP induction, although this did not reach statistical significance (Fig. $4 \mathrm{Bi}, \mathrm{Bii}$ ), possibly because only a proportion of hippocampal LIMK is activated by afferent activity. In fact, to our knowledge there are no previous reports 
showing phosphorylation of LIMK following hippocampal LTP induction. Interestingly, however, a significant reduction in the amount of pLIMK was observed in $\mathrm{RhoB}^{-1-}$ animals compared with $\mathrm{RhoB}^{+/+}$littermates, consistent with an impairment of LIMK function due to the loss of RhoB (Fig. 4Bi,Bii).

\section{Dendritic morphology and spine} density in the $\mathrm{RhoB}^{-/-}$mouse Given the discovery of a deficiency in cofilin phosphorylation in $\mathrm{RhoB}^{-1-}$ hippocampal slices following induction of synaptic plasticity, we investigated whether or not neuronal morphology in these mice was affected by the genetic deletion of RhoB. Previous studies have identified cortexspecific deficits induced by genetic modification of Rho GTPases (Hayashi et al., 2004). Detailed analysis of neuronal structure used Golgi-Cox staining of both $\mathrm{RhoB}^{+/+}$and $\mathrm{RhoB}^{-/-}$mouse brains to investigate dendritic structure and spine density in isolated pyramidal type cells from layer II/III of the cortex (Fig. $5 A, B$ ) and the CA1 region of the hippocampus (Fig. 5C). Layer II/III cortical cells from RhoB $^{-1-}$ animals exhibited a more complex branching pattern in areas proximal to the cell body compared with the same cell types in $\mathrm{RhoB}^{+/+}$animals $\left(\mathrm{RhoB}^{+/+}\right.$ vs RhoB $^{-1-}: 40 \mu \mathrm{m}, 15.37 \pm 0.78$ vs $16.75 \pm 0.7 ; 60 \mu \mathrm{m}, 13.82 \pm 0.77$ vs $16.03 \pm 0.79 ; 80 \mu \mathrm{m}, 10.488 \pm 0.76$ vs $12.48 \pm 0.91)$. No significant differences were seen in dendrites located more distal to the cell body (Fig. $5 A, B$ ). When the data were subdivided into distinct parts of the dendritic arbor, it was apparent that there was a significant increase in dendrite number in tissue from mice lacking RhoB only in the apical secondary dendrites (Fig. 5D). Similarly, there was an overall increase in the total length of dendrite within the maximum radius measured $(1615 \pm 52 \mu \mathrm{m}$ vs $1364 \pm 44$ $\mu \mathrm{m}^{-/-} \mathrm{vs}^{+/+} ;{ }^{\star * *} p<0.001 \mathrm{vs}^{+/+}$ group, $t$ test), and again in $\mathrm{RhoB}^{-1-}$ mice this effect was only significant in secondary apical dendrites (Fig. 5E). Interestingly, CA1 pyramidal cells in $\mathrm{RhoB}^{+/+}$and $\mathrm{RhoB}^{-1-}$ animals did not show any significant differences in branching patterns (Fig. 5C), although the possibility that there are small differences beyond the resolution of this analysis cannot be excluded.

We then went on to look at spine density in Golgi-stained hippocampal CA1 pyramidal cells in both $\mathrm{RhoB}^{+/+}$and $\mathrm{RhoB}^{-1-}$ mice. A dramatic $(62.1 \%)$ reduction in spine density was observed in secondary
A
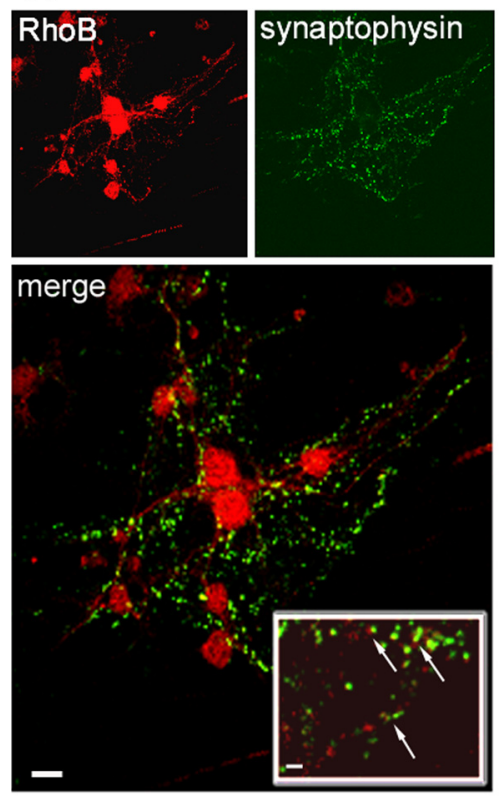

B
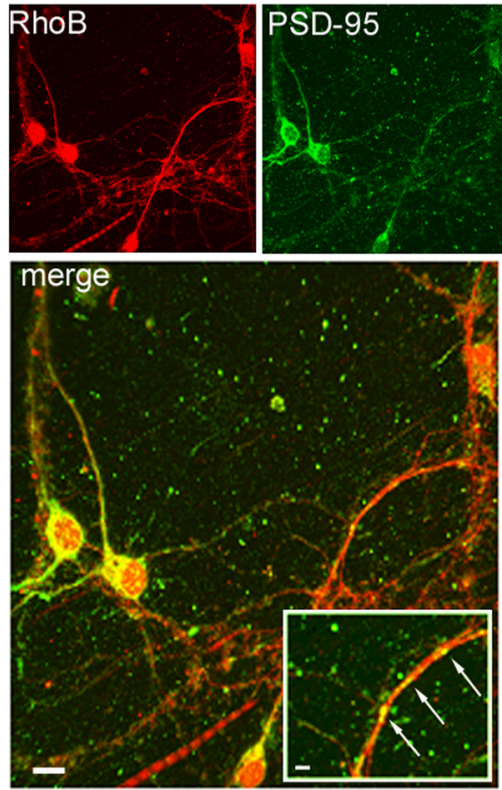

Figure 3. Localization of RhoB in corticohippocampal cultured neurons. $\boldsymbol{A}, \boldsymbol{B}$, Cultured corticohippocampal neurons were stained with anti-RhoB (red) and either anti-synaptophysin $(\boldsymbol{A})$ or anti-PSD-95 (B) (both green). Images show immunoreactive RhoB is in close apposition, but not colocalized, with immunoreactivity for the presynaptic marker synaptophysin $(\boldsymbol{A}$, merged image and inset), while there is a clear postsynaptic colocalization of immunoreactive RhoB with the immunoreactivity for the postsynaptic marker PSD-95 ( $\boldsymbol{B}$, merged image and inset), strongly suggesting a postsynaptic localization of RhoB. Scale bars, 10 $\mu \mathrm{m}$ in merged images and $2 \mu \mathrm{m}$ in insets.
B i $\begin{array}{cc}+/+ & -/- \\ \text { Control LTP } & \text { Control LTP }\end{array}$

PLIMK Total LIMK

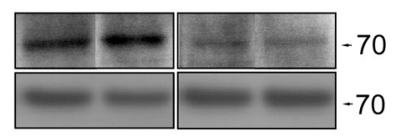

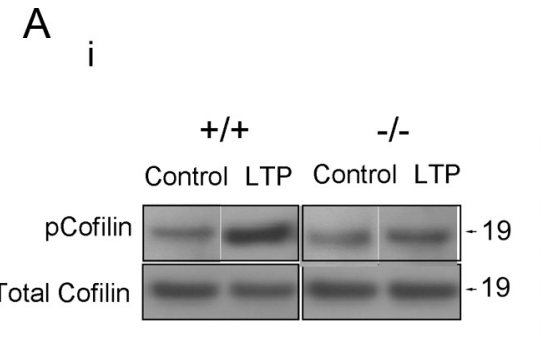

ii

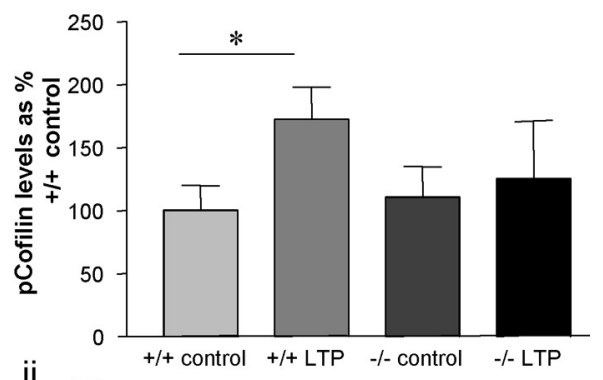

ii

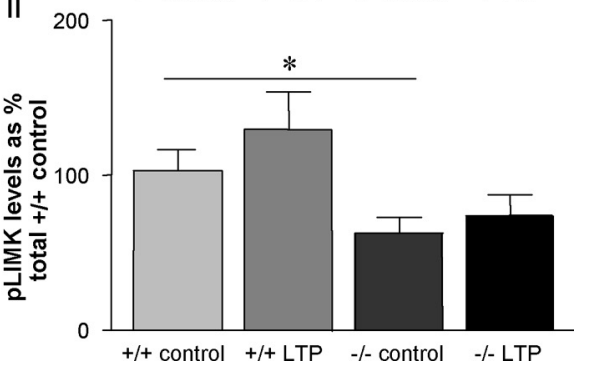

Figure 4. Western blot analysis of cofilin and LIMK phosphorylation in the CA1 hippocampal region from RhoB ${ }^{+/+}$and RhoB ${ }^{-I-}$ mice, following tetanus-induced LTP. Ai, Western blot images illustrating levels of pCofilin in isolated CA1 regions of hippocampal slices previously subjected to HFS and 15 min synaptic potentiation. Bands from RhoB ${ }^{+/+}(+/+)$animals show an increase in intensity following LTP induction. No change in band intensity is seen in tissue from RhoB $\mathrm{B}^{-/-}(-/-)$slices after LTP induction. Levels of total cofilin remained constant throughout the time course of the experiment. Aii, In acute RhoB ${ }^{+/+}$hippocampal slices, levels of phosphorylated cofilin were significantly increased $15 \mathrm{~min}$ following the delivery of a single highfrequency stimulation to the Schaffer collaterals of CA1 pyramidal cells. In RhoB ${ }^{-1-}$ animals, no increase in cofilin activation was observed following induction of LTP. Data are expressed as mean \pm SEM. Bi, Western blot images illustrating levels of pLIMK in isolated CA1 regions of hippocampal slices treated as in $\boldsymbol{A}$. Bii, Levels of phosphorylated LIMK showed a tendency to increase in Rho $\mathrm{B}^{+/+}$tissue following LTP induction, while pLIMK levels were significantly reduced in tissue from Rho $\mathrm{B}^{-1-}$ mice. $n=7-8$; ${ }^{*} p<0.05$ vs RhoB ${ }^{+/+}$control: two-way ANOVA followed by Tukeys post hoc analysis. Numbers $(\boldsymbol{A i}, \boldsymbol{B i})$ represent size markers (kilodaltons). 
A

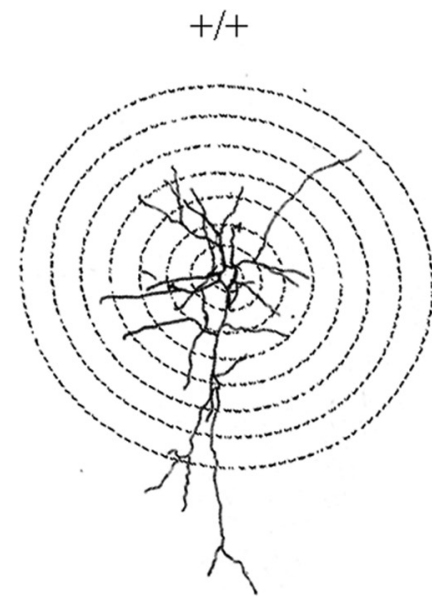

B

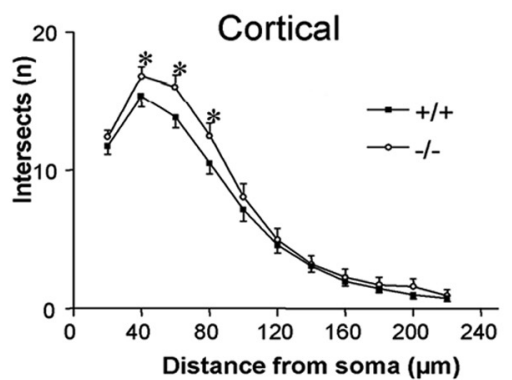

D

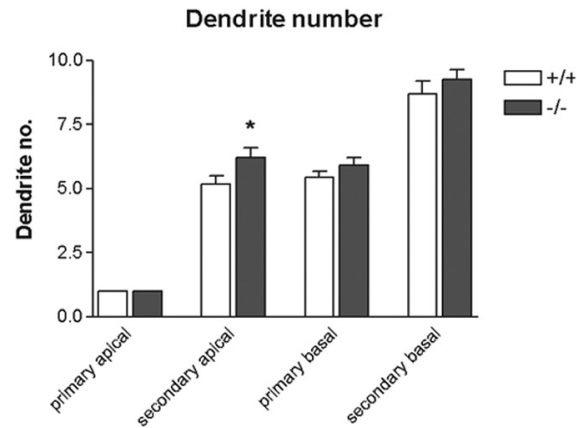

$-/-$

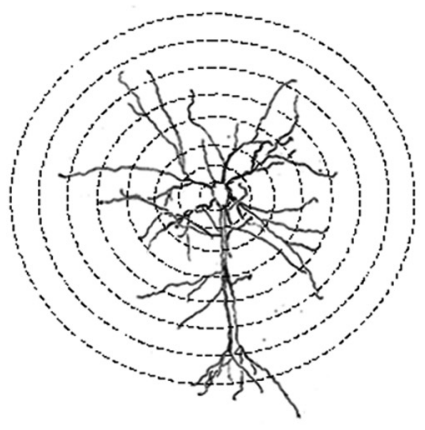

C

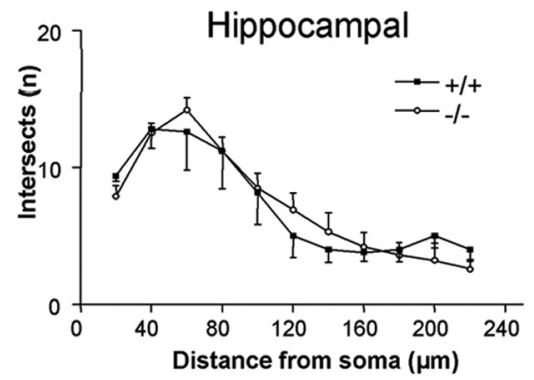

E

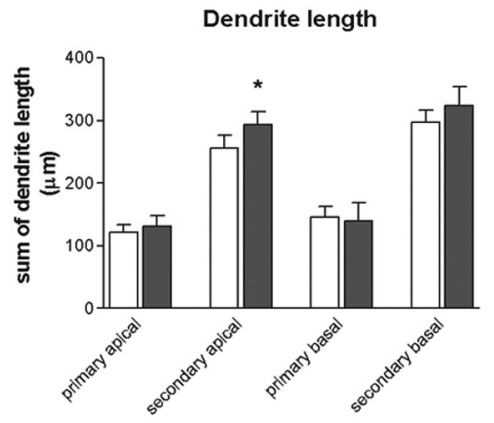

Figure 5. Morphological analysis of Golgi-stained neurons from cortical layer II/III and the CA1 region of the hippocampus. $A, B$, Sholl analysis of cortical neurons highlighted significant increases in branch points in cortical cells of RhoB ${ }^{-1-}$ $(-/-)$ mice (open circles) when compared with RhoB ${ }^{+/+}(+/+)$cells (black squares) in areas proximal $(40,60$, and 80 $\mu \mathrm{m})$ to the cell body layer. ${ }^{*} p<0.01$ versus RhoB ${ }^{+/+}$group: by four-way ANOVA followed by Tukey's post hoc analysis. No significant differences in branch pattern were observed in dendrites located further from the cell body. C, Sholl analysis of CA1 pyramidal cells in RhoB ${ }^{-/-}$and RhoB ${ }^{+/+}$mice following Golgi-Cox staining showed no significant differences in branching patterns throughout the dendritic tree. Data in $\boldsymbol{B}$ and $\boldsymbol{C}$ are expressed as a mean \pm SEM ( $n=3$ animals, 20-71 cells/genotype). $\boldsymbol{D}, \boldsymbol{E}$, Analysis of dendrite number $(\boldsymbol{D})$ and summed dendrite length $(\boldsymbol{E})$ separated into primary apical, secondary apical, primary basal, and secondary basal dendrites from cortical pyramidal neurones. ${ }^{*} p<0.05$ vs RhoB ${ }^{+/+}$ group, $t$ test.

dendrites in $\mathrm{RhoB}^{-1-}$ mice compared with $\mathrm{RhoB}^{+/+}$mice. A more modest but significant reduction in spine number was seen in tertiary dendrites $(31.5 \%)$, whereas no difference was seen in quaternary branches (Fig. 6C). A more detailed analysis of spines found on dendrites localized to stratum radiatum of the CA1 pyramidal layer revealed a significant increase in the proportion of stubby shaped spines at the expense of thin-shaped protrusions (thin spines: $\mathrm{RhoB}^{+/+} 27.17 \%$, RhoB $^{-/-} 21.62 \%$; stubby spines: RhoB ${ }^{+/+}$ $21.56 \%$, RhoB $\left.{ }^{-1-} 27.51 \%\right)$. No change in the number of mature, mushroom-shaped spines was observed (mushroom spines: $\mathrm{RhoB}^{+/+} 51.3 \%$, RhoB $^{-/-} 50.87 \%$ ) (Fig. 6D).
Spine morphology in the RhoB ${ }^{-/-}$mouse Given that dendritic spines are highly dynamic structures and that we have already identified that in the absence of RhoB they are subject to a change in number, we thought it critical to identify whether or not these structures were also subject to changes in their shape and/ or size. Intracellularly labeled CA1 pyramidal cells in $\mathrm{RhoB}^{+/+}$and RhoB ${ }^{-1-}$ mice were imaged using confocal microscopy, allowing for increased resolution at the level of the dendritic spine. Detailed analyses of spine length and neck and head diameter were conducted. Before assignment of each spine to an individual subtype (i.e., mushroom, thin, or stubby, see Materials and Methods), overall spine data showed a significant increase in spine length $\left(\mathrm{RhoB}^{+/+} 0.77 \pm 0.01, \mathrm{RhoB}^{-/-} 0.9 \pm\right.$ $0.02)$, head diameter $\left(\mathrm{RhoB}^{+/+} 0.587 \pm\right.$ $\left.0.01, \mathrm{RhoB}^{-/-} 0.67 \pm 0.01\right)$, and neck width $\left(\mathrm{RhoB}^{+/+} 0.45 \pm 0.01, \mathrm{RhoB}^{-/-}\right.$ $0.49 \pm 0.01)$ in $\mathrm{RhoB}^{-1-}$ animals compared with their $\mathrm{RhoB}^{+/+}$counterparts (Fig. 7A). Subclassification of spines into their appropriate spine subtypes using strict inclusion criteria elucidated that the increase in length was attributable to significant spine length increases in mushroom and thin-shaped spines, but not stubby spines (mushroom: $\mathrm{RhoB}^{+/+} 0.84 \pm$ 0.02, $\mathrm{RhoB}^{-1-} 1.04 \pm 0.02$, thin: $\mathrm{RhoB}^{+/+} 0.8 \pm 0.02, \mathrm{RhoB}^{-/-} 0.9 \pm$ 0.03 , stubby: $\mathrm{RhoB}^{+/+} 0.58 \pm 0.01$, RhoB $^{-l-} 0.61 \pm 0.02$ ) (Fig. $7 B$ ). The overall increase in head diameter was principally due to the increase in head width of mushroom spines $\left(\mathrm{RhoB}^{+/+} 0.65 \pm 0.01\right.$, $\left.\mathrm{RhoB}^{-1-} 0.77 \pm 0.01\right)$, although again a similar but not significant trend was evident with thin spines (Fig. 7C). Interestingly, although an overall increase in neck width was observed in $\mathrm{RhoB}^{-1-}$ mice, no individual subtype demonstrated such a significant effect, although a trend for increased neck width was certainly apparent (Fig. 7D). Indeed, the greatest morphological change appears to be attributed to the mushroom-type spines of $\mathrm{RhoB}^{-1-}$ animals, as these spines are longer and possess heads of greater diameter than those of $\mathrm{RhoB}^{+/+}$animals.

\section{Discussion}

The study aimed to investigate the role of RhoB in synaptic plasticity. Mice with genetic deletion of RhoB showed reduced synaptic plasticity accompanied by impaired cofilin phosphorylation and altered morphology of dendrites and spines.

\section{RhoB $^{-/-}$mice have altered neuronal morphology}

Alterations in spine density and morphology are closely correlated with synaptic plasticity (Fifková and Van Harreveld, 1977; Hosokawa et al., 1995; Engert and Bonhoeffer, 1999; Maletic- 
Savatic et al., 1999), and spine morphology is responsive to learning and aging (Bailey and Kandel, 1993; Harris and Kater, 1994). RhoA, Rac1, and CDC42 have all been implicated in the development and maintenance of dendritic structures, including spines (Luo et al., 1996; Nakayama et al., 2000; Tashiro et al., 2000). However, as evidence suggests that induction of LTP activates RhoB but not RhoA or Rac1 (O'Kane et al., 2003b), the hypothesis that RhoB mediates altered spine morphology during plasticity is attractive.

Cortical cells from $\mathrm{RhoB}^{-1-}$ mice showed increased arborization, implying a role for RhoB in the regulation of dendritic branching. Arborization is partially activity dependent (Inglis et al., 2002; Lee et al., 2005), and Rho proteins are reported to restrain dendritic outgrowth in cerebral cortex (Whitford et al., 2002). Our data implicate RhoB in this process. The effect of RhoB was observed in secondary but not primary apical dendrites. The functional significance of this change is unclear, although it is likely to alter the integrative properties of the neurons. It is, however, interesting that secondary dendrites may show more activity-dependent morphological plasticity than primary dendrites (Charych et al., 2006; Horton et al., 2007), and that basal and apical dendrites differ in their activity-dependent plasticity (Cook et al., 2004; Brown et al., 2005; Bose et al., 2010). The levels of RhoB in the rat and mouse CNS are high from around embryonic day 16 to birth, and then decrease slightly postnatally (Olenik et al., 1999; Komagome et al., 2000; Yoon et al., 2007). Embryonic RhoB in the CNS is expressed mainly in the cortical plate, raising the possibility that the some of the effects reported here may reflect compromised development of cortical and hippocampal neurones. Impaired processes in the development of cortical neurones have been implicated in a number of CNS diseases: for example Williams-Beuren syndrome, which is partially linked to dysfunctional LIMK, involves compromised cortical neuron development. The pathway identified here may hence be important for the optimal attainment of morphological phenotype in these neurones.

In hippocampal cells, we observed dramatic reductions in spine number. Additionally, spines appeared significantly longer, with significantly wider heads and necks. Traditionally, thin filopodial-like spines are associated with immature forms, while mushroom spines are thought to be mature forms that have increased in size during plasticity processes (Matsuzaki et al.,

C
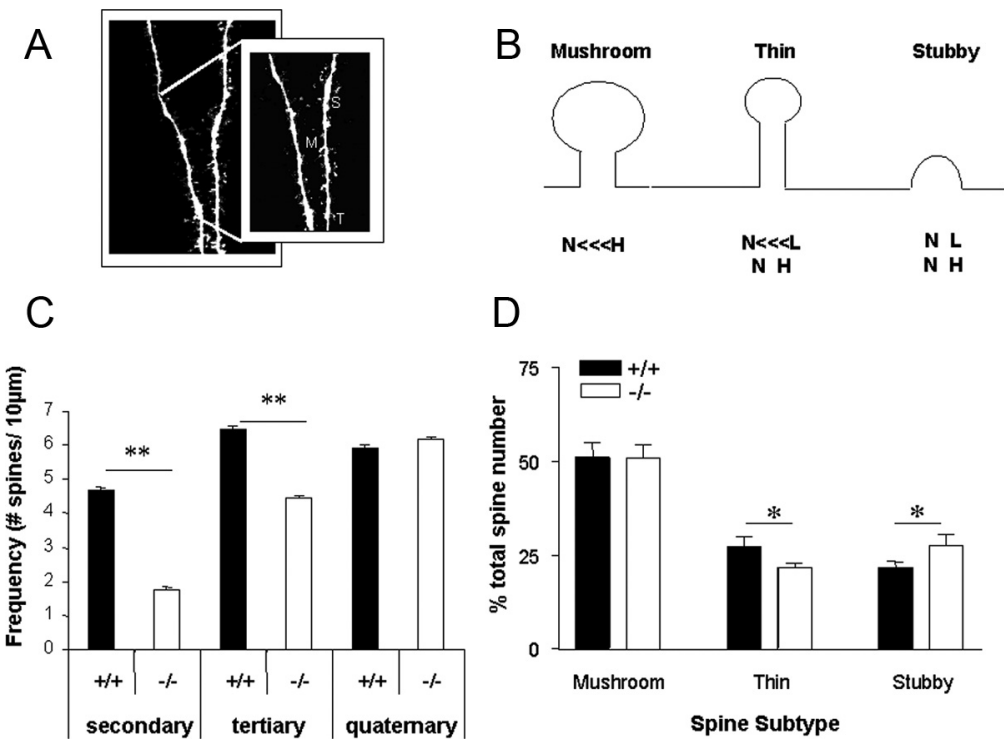

Figure 6. Dendritic spine analysis of labeled RhoB ${ }^{-/-}(-/-)$and RhoB ${ }^{+/+}(+/+)$CA1 pyramidal cells. $A$, Rhodamine red-filled dendrites from a CA1 pyramidal cell. Left, Confocal analysis generated high-resolution images of dendrites and dendritic spines from CA1 pyramidal cells. Right, Further manipulation of the image allowed increased resolution to measure the length and head and neck diameters of individual spines. M, Mushroom spine; $S$, stubby spine; T, thin spine. B, Spines that demonstrated a large head (H)-to-neck (N) ratio (>1.4) were defined as mushroom spines. Those spines whose length (L)-to-neck ratio was $>1.4$ were defined as thin spines. Stubby spines were labeled as such if their head-to-neck and length-to-neck ratio was $\leq 1$. C, Spine counts on secondary and tertiary dendritic branches in $\mathrm{RhOB}^{-1-} \mathrm{CA}$ 1 pyramidal cells show a dramatic reduction in the number of spines in both secondary and tertiary branches compared with $\mathrm{RhOB}^{+/+}$mice. № significant change in spine number on quaternary branches was observed. $\boldsymbol{D}$, Comparison of spine subtypes between $\mathrm{RhoB}^{-/-}$and $\mathrm{RhOB}^{+/+}$mice highlights a significantly increased percentage of stubby spines and a corresponding decrease in thin spines in dendritic branches located in stratum radiatum when expressed as a percentage of total spine number. Data are expressed as mean \pm SEM $\left(n=4\right.$ animals, 8 dendrites/genotype, 399 RhoB $^{+/+}$spines, 459 RhoB ${ }^{-1-}$ spines, ${ }^{*} p<0.05,{ }^{* *} p<0.01$ : two-way ANOVA followed by Tukey's post hoc analysis).
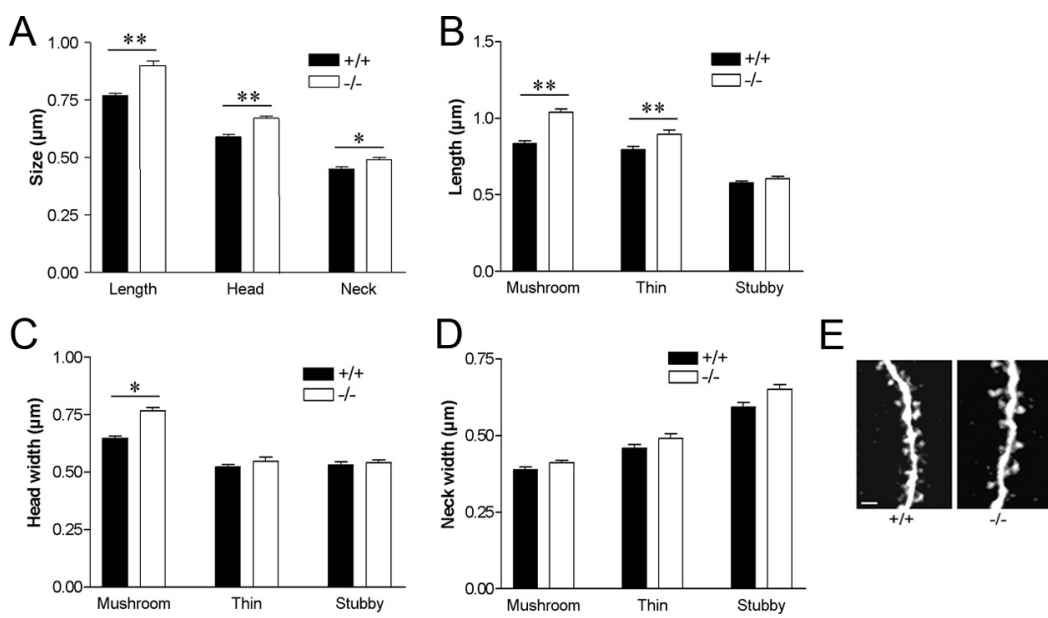

Figure 7. Morphological analysis of fluorescently labeled dendritic spines of RhoB ${ }^{-/-}(-/-)$and $\operatorname{RhoB}^{+/+}(+/+) \mathrm{CA} 1$ pyramidal neurons. $A$, Significant increases in overall spine length, head width, and neck widths were observed in dendritic spines from $R h B^{-1-}$ pyramidal cells compared with those from RhoB $B^{+1+}$ neurons. $B$, Subclassification of spines into either mushroom-, thin-, or stubby-type spines demonstrates that both mushroom- and thin-type spines are significantly longer in $\mathrm{RhoB}^{-/-}$than in RhoB ${ }^{+/+}$animals. However, no change in the length of stubby spines was observed. C, Only mushroom-type spines demonstrate a significant increase in head size. $\boldsymbol{D}$, No significant effect of genotype was observed on neck widths of individual subtypes. Data are expressed as mean \pm SEM ( $n=4$ animals/genotype, 8 dendrites/genotype, 399 spines ( $\left(R_{0} B^{+/+}\right), 459$ spines $\left(\mathrm{RhOB}^{-1-}\right)$. ${ }^{*} p<0.05,{ }^{* *} p<0.01$ : Kolmogorov-Smirnoff test). $\boldsymbol{E}$, Example of deconvolved stack images of pyramidal neuron tertiary dendrites showing spines from $\mathrm{RhOB}^{+/+}$and $\mathrm{RhOB}^{-/-}$mice; scale bar, $1 \mu \mathrm{m}$.

2004). It has been proposed that the ability to potentiate a synapse only recovers once spine size reverts to normal (Bourne and Harris, 2007). The results suggest that a mechanism to constrain spine expansion, or to shrink expanded spines back to normal 
size, is compromised in tissue lacking RhoB. Therefore, increased spine size could be associated with impaired plasticity.

\section{RhoB effectors modulate spine geometry}

Cofilin is implicated in the mechanisms of synaptic plasticity: its activity is inhibited through phosphorylation at Ser3 (Moriyama et al., 1996), reportedly via either Rac1 or RhoA (Yang et al., 1998; Sumi et al., 1999). Cofilin phosphorylation has been linked to increases in spine head volume (Fukazawa et al., 2003; Chen et al., 2007, Fedulov et al., 2007). Conversely, dephosphorylation has been linked to spine shrinkage (Zhou et al., 2004). Learning is also linked to increased pCofilin levels (Fedulov et al., 2007), as is the induction of LTP in hippocampal slices (Fukazawa et al., 2003, Chen et al., 2007). Similarly, we observed increased phosphorylation after LTP induction in $\mathrm{RhoB}^{+/+}$mice. However, in the $\mathrm{RhoB}^{-1-}$ mouse an almost complete absence of activitydependent cofilin phosphorylation suggests that RhoB is the major Rho GTPase linking synaptic activity to cofilin regulation.

We also observed a substantial reduction in basal levels of pLIMK in $\mathrm{RhoB}^{-1-}$ hippocampus compared with $\mathrm{RhoB}^{+/+}$animals, demonstrating that the LIMK/cofilin pathway is partially regulated by RhoB. Previous work examining LIMK1 ${ }^{-1-}$ cells showed that decreased pCofilin resulted in a predominance of stubby spines (Meng et al., 2002). Interestingly, we observed similar increases in stubby spines accompanied by reductions in thin spines. It is likely that disruption of the LIMK/cofilin pathway in the hippocampus of $\mathrm{RhoB}^{-1-}$ mice, leading to reduced activitydependent phosphorylation and hyperactivation of cofilin, contributes to our observation of altered spine composition.

The LIMK pathway is involved in lipid raft regulation (Lou et al., 2001) and the $\mathrm{RhoB}^{-1-}$ phenotype of reduced spine density, but increased spine size has been observed in neurons lacking lipid rafts (Hering et al., 2003). Lipid rafts are present in the dendrites of neurons, where they target Rho GTPases to the plasma membrane and allow coupling to downstream effectors. Indeed, lipid rafts compartmentalize the Rho-mDia signaling pathway, mediating microtubule stabilization (Palazzo et al., 2001). In neurons exposed to mDia2 small interfering RNA, spine phenotypes similar to those in the $\mathrm{RhoB}^{-1-}$ mouse were also observed (Hotulainen et al., 2009). It is highly likely that the spine phenotype observed in mDia2-deficient neurons reflects dysfunction of the same signaling cascade. Furthermore, mDia2 interacts specifically with RhoB on endosomes (Wallar et al., 2007). Interestingly, membrane trafficking from recycling endosomes is required for the growth and maintenance of dendritic spines, and reduced endosome number is associated with reduced spine density (Park et al., 2006).

\section{$\mathrm{RhoB}^{-/-}$mice have reduced short-term plasticity}

We previously demonstrated that LTP induction by HFS is associated with specific activation of RhoB via NMDA receptor stimulation (O'Kane et al., 2003b). Here, we show that while basal levels of synaptic transmission are normal, short-term plasticity was impaired in $\mathrm{RhoB}^{-1-}$ mouse hippocampus. Interestingly, the ROCK2 $2^{-1-}$ mouse, which shows a similar dendritic spine morphology phenotype in terms of reduced spine number and increased spine area and length, shows deficits in PPF and PTP (Zhou et al., 2009). Our immunolocalization indicated that RhoB is likely to be present postsynaptically rather than presynaptically. While PPF and PTP are commonly thought to be a function of presynaptic activity, several lines of evidence suggest that presynaptic function is affected by retrograde signaling from the postsynaptic site. For example, reduced PSD-95 modulates neu-

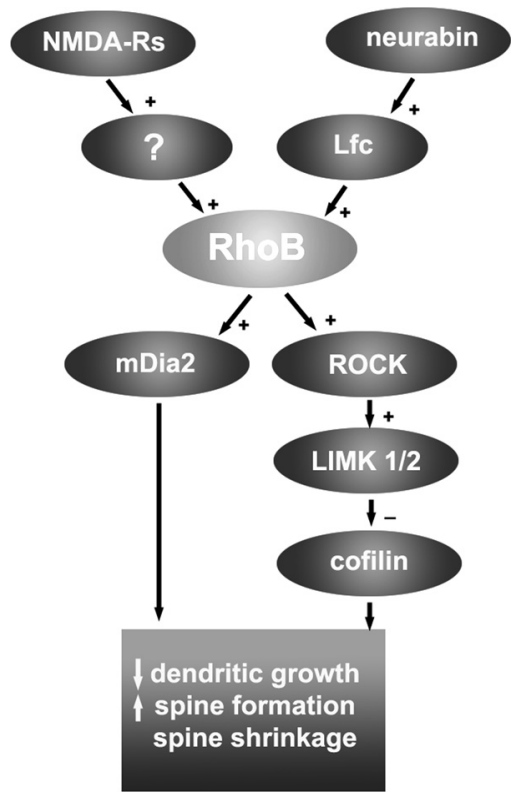

Figure 8. Roles of the Rho GTPase family in the regulation of neuronal morphology. While several Rho GTPases are involved in the complex and dynamic regulation of neuronal morphology, the data suggest that activity-dependent control over dendritic arborization and spine morphology involves RhoB via the pathway illustrated.

rotransmitter release in a retrograde manner, causing reduced presynaptic short-term plasticity (Futai et al., 2007). Furthermore, mice with partial deletion of PSD-95 have increased paired-pulse ratios (Migaud et al., 1998). PSD volume is closely correlated with spine size (Harris et al., 1992, Nikonenko et al., 2008) and $\mathrm{RhoB}^{-1-}$ mice have significantly larger dendritic spines. As such, our observations of reduced short-term plasticity may result from altered retrograde signaling linked to increases in the size of postsynaptic structures. Interestingly, several other proteins involved in trans-synaptic signaling, including integrin, N-cadherin, Eph-ephrin, and SAP97 (Regalado et al., 2006), maintain specific links to the Rho GTPases with regard to neuronal morphology (Schwartz and Shattil, 2000; Klein, 2004; Elia et al., 2006). Hence, while we cannot rule out the possibility that these short-term plasticity changes have a presynaptic locus, we favor the interpretation that they are postsynaptic in origin.

\section{RhoB $^{-l-}$ mice exhibit reduced eLTP and Cofilin phosphorylation}

We observed reduced eLTP in hippocampi from $\mathrm{RhoB}^{-1-}$ mice. Furthermore, this deficit was accompanied by an almost complete absence of activity-dependent cofilin phosphorylation. Increased phosphorylation of cofilin at Ser3 is associated with LTP induction (Fukazawa et al., 2003, Chen et al., 2007) whereas dephosphorylation has been linked to long-term depression (Zhou et al., 2004). Indeed, inhibition of this phosphorylation site results in reduced LTP (Fukazawa et al., 2003). Hence the deficit in activity-dependent cofilin phosphorylation in the $\mathrm{RhoB}^{-1-}$ mice may be causally related to the LTP deficit.

While the absence of the Rho effector ROCK2 reportedly leads to reduced basal levels of pCofilin in the hippocampus, activitydependent Cofilin phosphorylation is normal in ROCK2 ${ }^{-1-}$ animals (Zhou et al., 2009). Therefore, ROCK1 rather than ROCK2 may be involved in this effect of RhoB. In addition, we observed a reduction in the levels of pLIMK in the CA1 region of the hippocampus in mice lacking RhoB. Hence, the data suggest that an 
activity-dependent LIMK-cofilin pathway in the hippocampus is controlled by RhoB. However, this pathway may also functionally interact with other RhoB effectors such as $\mathrm{mDia}$, as has been noted in other systems (Geneste et al., 2002).

\section{Summary}

Rho GTPases have been implicated in the control of spine size and number (Luo et al., 1996) and dendritic morphology (Threadgill et al., 1997). Given that several neurological disorders relating to Rho dysfunction are accompanied by alterations in spine morphology and number (Irwin et al., 2000; Govek et al., 2004), it is important to determine how spine plasticity is controlled by Rho signaling molecules. There appears to be a complex interplay between closely related members of the Rho family and their effectors in the regulation of spine structure and function. The data reported here suggest that RhoB is particularly important for activity-dependent modifications (summarized in Fig. 8). RhoB is closely involved in the regulation of myosin in neurones (Conway et al., 2004), and altered myosin function may contribute to the effects reported here (Osterweil et al., 2005; Wang et al., 2008). It is also interesting to note that recent data implicate the interaction of dynamic microtubules with actin as a key regulator of spine morphology and synaptic plasticity (Jaworski et al., 2009). RhoB is unique among the Rho GTPase family in that, unlike its better-characterized siblings, it interacts strongly with the microtubule-associated protein MAP1A (LajoieMazenc et al., 2008) as well as with actin regulatory proteins. This exclusive interaction may link spine microtubule and actin filament dynamics and underlie the involvement of RhoB in the regulation of spine morphology reported here. Overall, our data suggest an important role for RhoB in synaptic plasticity and neuronal morphology.

\section{References}

Bailey CH, Kandel ER (1993) Structural changes accompanying memory storage. Annu Rev Physiol 55:397-426.

Bose M, Muñoz-Llancao P, Roychowdhury S, Nichols JA, Jakkamsetti V, Porter B, Byrapureddy R, Salgado H, Kilgard MP, Aboitiz F, DagninoSubiabre A, Atzori M (2010) Effect of the environment on the dendritic morphology of the rat auditory cortex. Synapse 64:97-110.

Bourne J, Harris KM (2007) Do thin spines learn to be mushroom spines that remember? Curr Opin Neurobiol 17:381-386.

Brabeck C, Mittelbronn M, Bekure K, Meyermann R, Schluesener HJ, Schwab JM (2003) Effect of focal cerebral infarctions on lesional RhoA and RhoB expression. Arch Neurol 60:1245-1249.

Brabeck C, Beschorner R, Conrad S, Mittelbronn M, Bekure K, Meyermann R, Schluesener HJ, Schwab JM (2004) Lesional expression of RhoA and RhoB following traumatic brain injury in humans. J Neurotrauma 21:697-706.

Brown SM, Henning S, Wellman CL (2005) Mild, short-term stress alters dendritic morphology in rat medial prefrontal cortex. Cereb Cortex 15:1714-1722.

Charych EI, Akum BF, Goldberg JS, Jornsten RJ, Rongo C, Zheng JQ, Firestein BL (2006) Activity-independent regulation of dendrite patterning by postsynaptic density protein PSD-95. J Neurosci 26:10164-10176.

Chen LY, Rex CS, Casale MS, Gall CM, Lynch G (2007) Changes in synaptic morphology accompany actin signaling during LTP. J Neurosci 27:5363-5372.

Conway AM, James AB, O’Kane EM, Rakhit S, Morris BJ (2004) Regulation of myosin light chain phosphorylation by RhoB in neuronal cells. Exp Cell Res 300:35-42.

Cook SC, Wellman CL (2004) Chronic stress alters dendritic morphology in rat medial prefrontal cortex. J Neurobiol 60:236-248.

Elia LP, Yamamoto M, Zang K, Reichardt LF (2006) p120 catenin regulates dendritic spine and synapse development through Rho-family GTPases and cadherins. Neuron 51:43-56.

Engert F, Bonhoeffer T (1999) Dendritic spine changes associated with hippocampal long-term synaptic plasticity. Nature 399:66-70.
Fedulov V, Rex CS, Simmons DA, Palmer L, Gall CM, Lynch G (2007) Evidence that long-term potentiation occurs within individual hippocampal synapses during learning. J Neurosci 27:8031-8039.

Fifková E, Van Harreveld A (1977) Long-lasting morphological changes in dendritic spines of dentate granular cells following stimulation of the entorhinal area. J Neurocytol 6:211-230.

Fukazawa Y, Saitoh Y, Ozawa F, Ohta Y, Mizuno K, Inokuchi K (2003) Hippocampal LTP is accompanied by enhanced F-actin content within the dendritic spine that is essential for late LTP maintenance in vivo. Neuron 38:447-460.

Futai K, Kim MJ, Hashikawa T, Scheiffele P, Sheng M, Hayashi Y (2007) Retrograde modulation of presynaptic release probability through signaling mediated by PSD-95-neuroligin. Nat Neurosci 10:186-195.

Geneste O, Copeland JW, Treisman R (2002) LIM kinase and Diaphanous cooperate to regulate serum response factor and actin dynamics. J Cell Biol 157:831-838.

Govek EE, Newey SE, Akerman CJ, Cross JR, Van der Veken L, Van Aelst L (2004) The X-linked mental retardation protein oligophrenin-1 is required for dendritic spine morphogenesis. Nat Neurosci 7:364-372.

Hall A (1998) Rho GTPases and the actin cytoskeleton. Science 279: $509-514$.

Harris KM, Kater SB (1994) Dendritic spines: cellular specializations imparting both stability and flexibility to synaptic function. Annu Rev Neurosci 17:341-371

Harris KM, Jensen FE, Tsao B (1992) Three-dimensional structure of dendritic spines and synapses in rat hippocampus (CA1) at postnatal day 15 and adult ages: implications for the maturation of synaptic physiology and long-term potentiation. J Neurosci 12:2685-2705.

Hayashi ML, Choi SY, Rao BS, Jung HY, Lee HK, Zhang D, Chattarji S, Kirkwood A, Tonegawa S (2004) Altered cortical synaptic morphology and impaired memory consolidation in forebrain-specific dominantnegative PAK transgenic mice. Neuron 42:773-787.

Hering H, Lin CC, Sheng M (2003) Lipid rafts in the maintenance of synapses, dendritic spines, and surface AMPA receptor stability. J Neurosci 23:3262-3271.

Horton AC, Yi JJ, Ehlers MD (2007) Cell type-specific dendritic polarity in the absence of spatially organized external cues. Brain Cell Biology 35:29-38.

Hosokawa T, Rusakov DA, Bliss TV, Fine A (1995) Repeated confocal imaging of individual dendritic spines in the living hippocampal slice: evidence for changes in length and orientation associated with chemically induced LTP. J Neurosci 15:5560-5573.

Hotulainen P, Llano O, Smirnov S, Tanhuanpää K, Faix J, Rivera C, Lappalainen P (2009) Defining mechanisms of actin polymerization and depolymerization during dendritic spine morphogenesis. J Cell Biol 185:323-339.

Inglis FM, Crockett R, Korada S, Abraham WC, Hollmann M, Kalb RG (2002) The AMPA receptor subunit GluR1 regulates dendritic architecture of motor neurons. J Neurosci 22:8042-8051.

Irwin SA, Galvez R, Greenough T (2000) Dendritic spine structural anomalies in fragile-X mental retardation syndrome. Cerebral Cortex 10:1038-1044.

Jaffe AB, Hall A (2005) Rho GTPases: biochemistry and biology. Annu Rev Cell Dev Biol 21:247-269.

James AB, Conway AM, Morris BJ (2006) Regulation of the neuronal proteasome by Zif268 (Egr1). J Neurosci 26:1624-1634.

Jaworski J, Kapitein LC, Gouveia SM, Dortland BR, Wulf PS, Grigoriev I, Camera P, Spangler SA, Di Stefano P, Demmers J, Krugers H, Defilippi P, Akhmanova A, Hoogenraad CC (2009) Dynamic microtubules regulate dendritic spine morphology and synaptic plasticity. Neuron 61:85-100.

Kamasani U, Prendergast GC (2005) Genetic response to DNA damage: proapoptotic targets of RhoB include modules for p53 response and susceptibility to Alzheimer's disease. Cancer Biol Ther 4:282-288.

Kamasani U, Duhadaway JB, Alberts AS, Prendergast GC (2007) mDia function is critical for the cell suicide program triggered by farnesyl transferase inhibition. Cancer Biol Ther 6:1422-1427.

Klein R (2004) Eph/ephrin signaling in morphogenesis, neural development and plasticity. Curr Opin Cell Biol 16:5 80-89.

Komagome R, Kimura K, Saito M (2000) Postnatal changes in Rho and Rho-related proteins in the mouse brain. Jpn J Vet Res 47:127-133.

Lajoie-Mazenc I, Tovar D, Penary M, Lortal B, Allart S, Favard C, Brihoum M, Pradines A, Favre G (2008) MAP1A light chain-2 interacts with GTP- 
RhoB to control epidermal growth factor (EGF)-dependent EGF receptor signaling. J Biol Chem 283:4155-4164.

Lee LJ, Lo FS, Erzurumlu RS (2005) NMDA receptor-dependent regulation of axonal and dendritic branching. J Neurosci 25:2304-2311.

Lee T, Winter C, Marticke SS, Lee A, Luo L (2000) Essential roles of Drosophila RhoA in the regulation of neuroblast proliferation and dendritic but not axonal morphogenesis. Neuron 25:307-316.

Leung T, Chen XQ, Manser E, Lim L (1996) The p160 RhoA-binding kinase ROK alpha is a member of a kinase family and is involved in the reorganization of the cytoskeleton. Mol Cell Biol 16:5313-5327.

Lin B, Kramár EA, Bi X, Brucher FA, Gall CM, Lynch G (2005) Theta stimulation polymerizes actin in dendritic spines of hippocampus. J Neurosci 25:2062-2069.

Liu A, Du W, Liu JP, Jessell TM, Prendergast GC (2000) RhoB alteration is necessary for apoptotic and antineoplastic responses to farnesyltransferase inhibitors. Mol Cell Biol 20:6105-6113.

Liu AX, Rane N, Liu JP, Prendergast GC (2001) RhoB is dispensable for mouse development, but it modifies susceptibility to tumor formation as well as cell adhesion and growth factor signaling in transformed cells. Mol Cell Biol 21:6906-6912.

Lou Z, Billadeau DD, Savoy DN, Schoon RA, Leibson PJ (2001) A role for a RhoA/ROCK/LIM-kinase pathway in the regulation of cytotoxic lymphocytes. J Immunol 167:5749-5757.

Luo L, Hensch TK, Ackerman L, Barbel S, Jan LY, Jan YN (1996) Differential effects of the Rac GTPase on Purkinje cell axons and dendritic trunks and spines. Nature 379:837-840.

Maletic-Savatic M, Malinow R, Svoboda K (1999) Rapid dendritic morphogenesis in CAl hippocampal dendrites induced by synaptic activity. Science 283:1923-1927.

Matsuzaki M, Honkura N, Ellis-Davies GC, Kasai H (2004) Structural basis of long-term potentiation in single dendritic spines. Nature 429:761-766.

McNair K, Davies CH, Cobb SR (2006) Plasticity-related regulation of the hippocampal proteome. Eur J Neurosci 23:575-580.

Meng Y, Zhang Y, Tregoubov V, Janus C, Cruz L, Jackson M, Lu WY, MacDonald JF, Wang JY, Falls DL, Jia Z (2002) Abnormal spine morphology and enhanced LTP in LIMK-1 knockout mice. Neuron $35: 121-133$

Migaud M, Charlesworth P, Dempster M, Webster LC, Watabe AM, Makhinson M, He Y, Ramsay MF, Morris RG, Morrison JH, O’Dell TJ, Grant SG (1998) Enhanced long-term potentiation and impaired learning in mice with mutant postsynaptic density-95 protein. Nature 396:433-439.

Moriyama K, Lida K, Yahara I (1996) Phosphorylation of Ser-3 of cofilin regulates its essential function on actin. Genes Cells 1:73-86.

Nägerl UV, Eberhorn N, Cambridge SB, Bonhoeffer T (2004) Bidirectional activity-dependent morphological plasticity in hippocampal neurons. Neuron 44:759-767.

Nakayama AY, Harms MB, Luo L (2000) Small GTPases Rac and Rho in the maintenance of dendritic spines and branches in hippocampal pyramidal neurons. J Neurosci 20:5329-5338.

Nikonenko I, Boda B, Steen S, Knott G, Welker E, Muller D (2008) PSD-95 promotes synaptogenesis and multiinnervated spine formation through nitric oxide signaling. J Cell Biol 183:1115-1127.

Okamoto K, Nagai T, Miyawaki A, Hayashi Y (2004) Rapid and persistent modulation of actin dynamics regulates postsynaptic reorganization underlying bidirectional plasticity. Nat Neurosci 7:1104-1112.

O'Kane EM, Stone TW, Morris BJ (2003a) Distribution of Rho family GTPases in the adult rat hippocampus and cerebellum. Brain Res Mol Brain Res 114:1-8.

O'Kane EM, Stone TW, Morris BJ (2003b) Activation of Rho GTPases by synaptic transmission in the hippocampus. J Neurochem 87:1309-1312.

O'Kane EM, Stone TW, Morris BJ (2004) Increased long-term potentiation in the CA1 region of rat hippocampus via modulation of GTPase signalling or inhibition of Rho kinase. Neuropharmacology 46:879-887.

Olenik C, Aktories K, Meyer DK (1999) Differential expression of the small GTP-binding proteins RhoA, RhoB, Cdc42u and Cdc42b in developing rat neocortex. Mol Brain Res 70:9-17.
Osterweil E, Wells DG, Mooseker MS (2005) A role for myosin VI in postsynaptic structure and glutamate receptor endocytosis. J Cell Biol 168:329-338.

Palazzo AF, Cook TA, Alberts AS, Gundersen GG (2001) mDia mediates Rho-regulated formation and orientation of stable microtubules. Nat Cell Biol 3:723-729.

Park M, Salgado JM, Ostroff L, Helton TD, Robinson CG, Harris KM, Ehlers MD (2006) Plasticity-induced growth of dendritic spines by exocytic trafficking from recycling endosomes. Neuron 52:817-830.

Rakhit S, Clark CJ, O'Shaughnessy CT, Morris BJ (2005) N-methyl-Daspartate and brain-derived neurotrophic factor induce distinct profiles of extracellular signal-regulated kinase, mitogen- and stress-activated kinase, and ribosomal s6 kinase phosphorylation in cortical neurons. Mol Pharmacol 67:1158-1165.

Regalado MP, Terry-Lorenzo RT, Waites CL, Garner CC, Malenka RC (2006) Transsynaptic signaling by postsynaptic synapse-associated protein 97. J Neurosci 26:2343-2357.

Sandilands E, Cans C, Fincham VJ, Brunton VG, Mellor H, Prendergast GC, Norman JC, Superti-Furga G, Frame MC (2004) RhoB and actin polymerization coordinate Src activation with endosome-mediated delivery to the membrane. Dev Cell 7:855-869.

Sarner S, Kozma R, Ahmed S, Lim L (2000) Phosphatidylinositol 3-kinase, $\mathrm{Cdc42}$, and Rac1 act downstream of Ras in integrin-dependent neurite outgrowth in N1E-115 neuroblastoma cells. Mol Cell Biol 20:158-172.

Schwartz MA, Shattil SJ (2000) Signaling networks linking integrins and rho family GTPases. Trends Biochem Sci 25:388-391.

Scott EK, Reuter JE, Luo L (2003) Small GTPase Cdc42 is required for multiple aspects of dendritic morphogenesis. J Neurosci 23:3118-3123.

Simpson CS, Morris BJ (2000) Regulation of neuronal cell adhesion molecule expression by NF-kappa B. J Biol Chem 275:16879-16884.

Sumi T, Matsumoto K, Takai Y, Nakamura T (1999) Cofilin phosphorylation and actin cytoskeletal dynamics regulated by rho- and Cdc42activated LIM-kinase 2. J Cell Biol 147:1519-1532.

Tashiro A, Minden A, Yuste R (2000) Regulation of dendritic spine morphology by the rho family of small GTPases: antagonistic roles of Rac and Rho. Cereb Cortex 10:927-938.

Threadgill R, Bobb K, Ghosh A (1997) Regulation of dendritic growth and remodeling by Rho, Rac, and Cdc42. Neuron 19:625-634.

Tigyi G, Fischer DJ, Sebök A, Yang C, Dyer DL, Miledi R (1996) Lysophosphatidic acid-induced neurite retraction in PC12 cells: control by phosphoinositide-Ca2+ signaling and Rho. J Neurochem 66:537-548.

Wallar BJ, Deward AD, Resau JH, Alberts AS (2007) RhoB and the mammalian Diaphanous-related formin mDia2 in endosome trafficking. Exp Cell Res 313:560-571.

Wang Z, Edwards JG, Riley N, Provance DW Jr, Karcher R, Li XD, Davison IG, Ikebe M, Mercer JA, Kauer JA, Ehlers MD (2008) Myosin Vb mobilizes recycling endosomes and AMPA receptors for postsynaptic plasticity. Cell 135:535-548.

Whitford KL, Dijkhuizen P, Polleux F, Ghosh A (2002) Molecular control of cortical dendrite development. Annu Rev Neurosci 25:127-149.

Yang N, Higuchi O, Ohashi K, Nagata K, Wada A, Kangawa K, Nishida E, Mizuno K (1998) Cofilin phosphorylation by LIM-kinase 1 and its role in Rac-mediated actin reorganization. Nature 393:809-812.

Yoon YS, Choo JH, Yoo T, Kang K, Chung JH (2007) RhoB is epigenetically regulated in an age- and tissue-specific manner. Biochem Biophys Res Commun 362:164-169.

Zhang Z, Ottens AK, Larner SF, Kobeissy FH, Williams ML, Hayes RL, Wang KK (2006) Direct Rho-associated kinase inhibiton induces cofilin dephosphorylation and neurite outgrowth in PC-12 cells. Cell Mol Biol Lett 11:12-29.

Zhou Q, Homma KJ, Poo MM (2004) Shrinkage of dendritic spines associated with long-term depression of hippocampal synapses. Neuron 44: $749-757$.

Zhou Z, Meng Y, Asrar S, Todorovski Z, Jia Z (2009) A critical role of Rhokinase ROCK2 in the regulation of spine and synaptic function. Neuropharmacology 56:81-89. 